\title{
Intra-operative gallbladder scoring predicts conversion of laparoscopic to open cholecystectomy: a WSES prospective collaborative study
}

Michael Sugrue ${ }^{1 *}$ D, Federico Coccolini ${ }^{2}$, Magda Bucholc ${ }^{3}$, Alison Johnston ${ }^{1}$ and Contributors from WSES

\begin{abstract}
Introduction: Laparoscopic cholecystectomy, the gold-standard approach for cholecystectomy, has surprisingly variable outcomes and conversion rates. Only recently has operative grading been reported to define disease severity and few have been validated. This multicentre, multinational study assessed an operative scoring system to assess its ability to predict the need for conversion from laparoscopic to open cholecystectomy.

Methods: A prospective, web-based, ethically approved study was established by WSES with a 10-point gallbladder operative scoring system; enrolling patients undergoing elective or emergency laparoscopic cholecystectomy between January 2016 and December 2017. Gallbladder surgery was considered easy if the G10 score < 2, moderate $(2 \leqq 4)$, difficult $(5 \leqq 7)$ and extreme $(8 \leqq 10)$. Demographics about the patients, surgeons and operative procedures, use of cholangiography and conversion rates were recorded.

Results: Five hundred four patients, mean age 53.5 (range 18-89), were enrolled by 55 surgeons in 16 countries. Surgery was performed by consultants in $70 \%$ and was elective in (56\%) with a mean operative time of $78.7 \mathrm{~min}$ (range 15-400). The mean G10 score was 3.21, with 22\% deemed to have difficult or extreme surgical gallbladders, and $71 / 504$ patients were converted. The G10 score was 2.98 in those completed laparoscopically and 4.65 in the 71/504 (14\%) converted. ( $p<0.0001$; AUC 0.772 (Cl 0.719-0.825). The optimal cut-off point of 0.067 (score of 3 ) was identified in G10 vs conversion to open cholecystectomy. Conversion occurred in 33\% of patients with $\mathrm{G} 10$ scores of $\geq 5$. The four variables statistically predictive of conversion were $G B$ appearance-completely buried $G B$, impacted stone, bile or pus outside GB and fistula.

Conclusion: The G10 operative scores provide simple grading of operative cholecystectomy and are predictive of the need to convert to open cholecystectomy. Broader adaptation and validation may provide a benchmark to understand and improve care and afford more standardisation in global comparisons of care for cholecystectomy.
\end{abstract}

Keywords: Cholecystitis, Operative severity scoring system, Conversion to open cholecystectomy, Index surgery, Surgical outcomes

\footnotetext{
* Correspondence: michael.sugrue@hse.ie

'Donegal Clinical Research Academy, Letterkenny University Hospital,

Donegal, Ireland

Full list of author information is available at the end of the article
}

(c) The Author(s). 2019 Open Access This article is distributed under the terms of the Creative Commons Attribution 4.0 International License (http://creativecommons.org/licenses/by/4.0/), which permits unrestricted use, distribution, and reproduction in any medium, provided you give appropriate credit to the original author(s) and the source, provide a link to the Creative Commons license, and indicate if changes were made. The Creative Commons Public Domain Dedication waiver (http://creativecommons.org/publicdomain/zero/1.0/) applies to the data made available in this article, unless otherwise stated. 


\section{Introduction}

Laparoscopic cholecystectomy not only is the cornerstone of management of biliary disease and cholecystitis but is one of the commonest operations in both elective and emergency surgery. It offers an unquestionable advantage over open cholecystectomy to the patient and the health care system [1]. It is essential therefore that simple metrics can be applied to understanding the course of surgery and its outcome. While completion of the operation laparoscopically is not a proven quality indicator, analysis of surgical performance needs greater scrutiny [2-4]. Outcomes from cholecystectomy, particularly in terms of operative approaches and findings, use of intra-operative cholangiography, conversion from laparoscopic to open, length of surgery and morbidity, including readmission to hospital, vary. There are many variables in the management of cholecystitis, requiring a tailored approach due in part to the large heterogeneity of the patients and the actual state of the gallbladder at surgery. Interpreting the cause of and reducing this variability is a key to advancing outcomes following laparoscopic cholecystectomy.9 Conversion to open cholecystectomy is itself not only occasionally a necessity but a safer option than proceeding laparoscopically. Surgeons, with far greater exposure to laparoscopic technique, may opt for different damage control procedures rather than conversion to open, including various forms of bailout techniques [5].

It is important therefore that there is standardization of documentation and communication, with risk-adjusted measures, to allow qualitative studies and outcome comparisons. Accurate and reproducible stratification of the severity of gallbladder (GB) disease requires a scoring/ grading system that is easily implemented, clinically and operatively relevant and simple. A number of publications have reported new scoring and grading systems [6-10]. Some of these scores are based on preoperative clinical findings, and imaging, but only concentrate on actual operative findings limiting their use. Recently, the AAST scoring system has been validated and it has been suggested that it is superior to the 2013 Tokyo classification in part due to the greater number of grades of cholecystitis with the AAST classification [11]. The Tokyo guidelines for classifying cholecystitis use three grades, without robust inclusion of the operative findings [12]. More recently, the Tokyo updates have expanded the potential scoring-grading system, but this remains yet to be validated.

As surgeons practising in both elective and emergency general surgery, we are well aware that the operative findings and difficulty hold the key to outcome.

We reported a 10-point operative scoring system of cholecystitis severity to facilitate a potential benchmark for international analysis [7].
This study undertook a prospective evaluation of a recently reported intra-operative G10 gallbladder scoring system to determine if it could predict the outcome of surgery, primarily the ability to complete the operation laparoscopically.

\section{Methods}

A prospective ethically approved multicentre study was undertaken, between January 2016 and December 2017, under the leadership of the World Society of Emergency Surgery. An open invitation was sent to surgeons to register and enrol their patients undergoing laparoscopic cholecystectomies, either as elective or emergency procedures. Data was entered in a web-based data entry sheet [13]. Surgeons registered on-line and then enrolled their de-identified patient data, after completion of surgery, to include demographics, patient age, gender, nature of surgery either elective or emergency surgery, into a 10-point intra-operative gallbladder scoring system (G10) (Table 1). The G10 cholecystitis severity score focuses on four key components: the gallbladder's operative appearance, whether distended or contracted, ease of access and the presence of sepsis in the peritoneal cavity, either biliary peritonitis or purulent fluid, and/or a cholecysto-enteric fistula. The scoring system differed very slightly from Sugrue's original published 10-point operative score with the addition of an extra category for the degree of gallbladder adhesions (scoring 2 points). The previous (single point) score for time to identify the cystic artery and duct was removed and replaced with a category which considered limited access due to adhesions from previous surgery.

Table 1 Cholecystitis severity score used for G10

\begin{tabular}{ll}
\hline Cholecystitis severity & Score \\
\hline Appearance & 1 \\
Adhesions < 50\% of GB & 2 \\
Adhesions $>50 \%$ but GB buried & 3 (max) \\
Completely buried GB & \\
Distension/contraction & 1 \\
Distended GB or contracted shrilled GB & 1 \\
Inability to grasp without decompression & 1 \\
Stone > 1 cm impacted in Hartmann's pouch & \\
Access & 1 \\
BMI > 30 & 1 \\
Adhesions from previous surgery limiting surgery & \\
Sepsis and complications & 1 \\
Free bile or pus outside the gallbladder & 1 \\
Fistula & 10 \\
Total possible
\end{tabular}


Further information was recorded relating to the occurrence of intra-operative complications, use of intra-operative cholangiography (IOC), and previous intervention of the common bile duct (CBD). The surgeons documented whether the procedure was completed laparoscopically or converted to open. In addition, the definitive type of cholecystectomy performed either total or subtotal cholecystectomy was noted. The operative time and level of experience of the surgeon was recorded. Patient identifiers were limited to the patients' age, date of procedure, the email of the surgeon and the Centre. The relationship of the surgical volume to open conversion was explored. A non-parametric Spearman test was used to assess the strength of the relationship between the number of operations per-consultant and percent converted from laparoscopic to open cholecystectomy.

Gallbladder surgery was considered easy if the G10 score $<2$, moderate $(2 \leqq 4)$, difficult $(5 \leqq 7)$ and extreme $(8 \leqq 10)$.

Descriptive data was presented as mean, standard deviation and range. Mann-Whitney $U$ test was used to evaluate the significance of differences between continuous variables. Fisher exact test was used to find the significant association between the G10 score and the outcome. A $p$ value $<0.05$ represented statistical significance. Univariate analysis was performed to identify risk factors associated with conversion to open cholecystectomy. Variables with a $p$ value $<0.1$, i.e. GB appearance, adhesions from previous surgery, impacted stone, bile or pus outside $G B$, distended or shrivelled GB, inability to grasp without decompression and fistula, were considered clinically relevant (Table 2) and entered into the logistic regression model. The accuracy of G10 to predict conversion to open cholecystectomy was assessed using the area under the receiver operating curves (AUR) with 95\% confidence intervals (CI). ROC curve and its area under the curve (AUC) were calculated for the accuracy in predicting the outcome (i.e. no conversion to open cholecystectomy vs conversion to open cholecystectomy) based on G10 scores.

Table 2 G10 score and conversion rates

\begin{tabular}{lll}
\hline G10 & \multicolumn{2}{l}{ Conversion to open cholecystectomy (\%) } \\
\cline { 2 - 3 } & No & Yes \\
\hline 1 & 96.6 & 3.4 \\
2 & 97.5 & 2.5 \\
3 & 87.6 & 12.4 \\
4 & 81.7 & 18.3 \\
5 & 70.4 & 29.6 \\
6 & 66.7 & 33.3 \\
7 & 68.4 & 31.6 \\
8 & 33.3 & 66.7 \\
\hline
\end{tabular}

\section{Results}

Five hundred four patients, mean age 53.5 (range 1889 ), were enrolled by 55 surgeons in 16 countries. Two hundred ninety-five out of five hundred four (58.5\%) were female and 284/504 (56.3\%) were over the age of 50 years. Surgery was elective in 281/504 (56\%). The mean number of laparoscopic cholecystectomies each surgeon performed was $9.2 \pm 12.9$, (range 1-63). The mean conversion rate to open surgery was $14.3 \%$, range $0-100 \%$. The conversion rate was $7.5 \%$ in elective and $22.4 \%$ in emergency cases. The conversion rate was $15.1 \%$ for surgeons performing $\geq 5$ cases. Surgery was performed by consultants in $353 / 504$ (70\%) of which $57 \%$ was elective, compared to $66 \%$ for residents. The mean operative time was $78.7 \mathrm{~min}$ (range 15-400). This was $71.8 \mathrm{~min}(15-400)$ for elective and $87.3 \mathrm{~min}$ (24$278)$ for emergency cases respectively $(p \leq 0.0001)$.

Minor adhesions to the GB (covering $<50 \%$ of gallbladder) were found in 94/223 (42.4\%) emergency and 192/ $281(68.3 \%)$ in elective cases. GB adhesions $>50 \%$ occurred in 64/223 (28.7\%) emergency compared to $67 / 281$ (23.8\%) elective and completely buried in 65/281 (23.1\%) emergency compared to $22 / 281$ (7.8\%) in elective cases.

A distended or contracted/shrivelled gallbladder was found in 118/223 (52.9\%) of emergency surgeries compared to $105 / 281(37.4 \%)$ of elective $(p=0.004)$. Similarly, bile and pus indicative of evolving biliary peritonitis were found in $61 / 223(27.4 \%)$ of emergency cases and $5 / 281(1.8 \%)$ of elective $(p=0.0001)$. The relationship between risk factors and conversion are shown in Table 2. Univariate analysis of risk factors for conversion is shown in Table 3. Following multivariate analysis factors predictive of conversion to open cholecystectomy included a completely buried gallbladder, a stone impacted in Hartmann's pouch, biliary peritonitis and a fistula (Table 4). Overall, 112/504 (22.2\%) patients were found to have a difficult or extreme degree of operative difficulty as judged by a G10 score of 5 or greater.

Operative cholangiograms were performed in 68/504 (13\%). Prior ERCP was performed in 79/504 (16\%).

The overall mean G10 score was $3.2 \pm 1.7$ and $3.0 \pm 1.6$ in the $433 / 504(85.9 \%)$ completed laparoscopically and $4.7 \pm 1.7$ in the $71 / 504(14.1 \%)$ converted $(p=5.274 \mathrm{e}-10$, $p<0.0001$; AUC (95\% CI) was 0.772 (0.719-0.825). By maximizing sensitivity + specificity across various cut-off points, the optimal cut-off point of $0.067(\mathrm{G} 10=3)$ was identified in $\mathrm{G} 10$ vs conversion to open cholecystectomy.

Conversion occurred in $33 \%$ of patients with G10 scores of $\geq 5$. Thirty patients were reported as having intra-operative complications $22 / 30$ (73\%) occurring in the easy or moderate disease severity category.

A Fisher $p$ value $=5.274 \mathrm{e}-10$ shows that $\mathrm{G} 10$ score is significantly associated with the conversion to open cholecystectomy. 
Table 3 Risk factors for conversion to open cholecystectomy in univariate analysis

\begin{tabular}{lll}
\hline Risk factor & OR $(95 \% \mathrm{Cl})$ & $p$ value \\
\hline Gallbladder (GB) appearance & $3.43(2.38,4.94)$ & $<0.0001^{* * *}$ \\
BMI & $1.04(0.64,1.68)$ & 0.891 \\
Adhesions from previous surgery limiting access & $3.14(1.71,5.75)$ & $0.0005^{* * *}$ \\
Distended or shrivelled GB & $1.72(1.16,2.55)$ & $0.0018^{* *}$ \\
Inability to grasp GB & $1.92(1.25,2.95)$ & $0.0013^{* *}$ \\
Stone $>1$ cm impacted in Hartmann's pouch & $2.14(1.39,3.3)$ & $0.0002^{* * *}$ \\
Bile or pus outside GB & $3.99(2.33,6.83)$ & $<0.0001^{* * *}$ \\
Fistula & $10.5(2.48,44.43)$ & $0.0019^{* *}$ \\
\hline
\end{tabular}

** - statistically significant at the 0.01 level

*** - statistically significant at the 0.001 level

The relationship between the number of cholecystectomies performed and conversion is shown in Fig. 1 with conversion rates higher in those undertaking smaller numbers. The correlation coefficient rho $=-0.17$ suggests a negative, but relatively weak, correlation between these two variables-implying a higher conversion rate for individuals performing fewer operations.

Table 5 shows an analysis of outcome with risk factors for intra-operative complications.

\section{Discussion}

There is an unquestionable unmet need for robust, reproducible metrics to allow understanding of disease severity in patients with cholecystitis [14]. Defining the status of the gallbladder at surgery and the degree of any cholecystitis will facilitate more standardised reporting and improve pathways and management of risk-adjusted outcomes $[15,16]$. Since Carl Langenbuch reported the first open cholecystectomy in 1882 and Muhe the first laparoscopic cholecystectomy in 1985 surprisingly it is only recently there has been increasing attention to grading severity of cholecystitis [7, 17]. There is now an agreement that we need to gain insight into the heterogeneity of cholecystitis and variance in outcome [18]. In the 1980s and 1990s, Hanna et al. and Nassar et al. described simple scales of difficulty for cholecystectomy $[19,20]$. When we reported the G10 operative scoring system in 2015, we identified 16 published GB grading systems. Since then, there has been a number reported [10]. Confounding the variability of operative findings

Table 4 Risk factors for conversion to open cholecystectomy in multivariate

\begin{tabular}{|c|c|c|c|c|c|}
\hline \multirow[t]{2}{*}{ Risk factor } & \multirow[t]{2}{*}{ Level } & \multicolumn{2}{|l|}{ Outcome } & \multirow{2}{*}{$\begin{array}{l}\text { Multivariate odds } \\
\text { ratios }(95 \% \mathrm{Cls})\end{array}$} & \multirow[t]{2}{*}{$p$ value } \\
\hline & & $\begin{array}{l}\text { No conversion to } \\
\text { open cholecystectomy } \\
\text { no. (\%) }\end{array}$ & $\begin{array}{l}\text { Conversion to } \\
\text { open cholecystectomy } \\
\text { no. (\%) }\end{array}$ & & \\
\hline \multirow[t]{3}{*}{ Gallbladder (GB) appearance } & Adhesions covering $<50 \%$ of GB & $264(92.3 \%)$ & $22(7.7 \%)$ & & \\
\hline & Adhesions $>50 \%$ but GB visible & $111(84.7 \%)$ & $20(15.3 \%)$ & $1.41(0.71,2.82)$ & 0.3264 \\
\hline & Completely buried GB & $58(66.7 \%)$ & $29(33.3 \%)$ & $2.50(1.17,5.33)$ & $0.018^{*}$ \\
\hline \multirow{2}{*}{$\begin{array}{l}\text { Adhesions from previous } \\
\text { surgery limiting access }\end{array}$} & No & $397(88 \%)$ & $54(12 \%)$ & \multirow[t]{2}{*}{$2.05(0.99,4.25)$} & \multirow[t]{2}{*}{0.055} \\
\hline & Yes & $36(67.9 \%)$ & $17(32.1 \%)$ & & \\
\hline \multirow[t]{2}{*}{ Distended or shrivelled GB } & No & $254(90.4 \%)$ & $27(9.6 \%)$ & \multirow[t]{2}{*}{$1.52(0.86,2.69)$} & \multirow[t]{2}{*}{0.1508} \\
\hline & Yes & $179(80.3 \%)$ & $44(19.7 \%)$ & & \\
\hline \multirow[t]{2}{*}{ Inability to grasp GB } & No & $311(89.4 \%)$ & $37(10.6 \%)$ & \multirow[t]{2}{*}{$1.30(0.72,2.33)$} & \multirow[t]{2}{*}{0.3796} \\
\hline & Yes & $122(78.2 \%)$ & $34(21.8 \%)$ & & \\
\hline \multirow{2}{*}{$\begin{array}{l}\text { Stone }>1 \mathrm{~cm} \text { impacted in } \\
\text { Hartmann's pouch }\end{array}$} & No & $322(89.7 \%)$ & $37(10.3 \%)$ & \multirow[t]{2}{*}{$1.96(1.09,3.55)$} & \multirow[t]{2}{*}{$0.0257^{*}$} \\
\hline & Yes & $111(76.6 \%)$ & $34(23.4 \%)$ & & \\
\hline \multirow[t]{2}{*}{ Bile or pus outside GB } & No & $391(89.3 \%)$ & $47(10.7 \%)$ & \multirow[t]{2}{*}{$2.75(1.37,5.53)$} & \multirow[t]{2}{*}{$0.0046^{* *}$} \\
\hline & Yes & $42(63.6 \%)$ & $24(36.4 \%)$ & & \\
\hline \multirow[t]{2}{*}{ Fistula } & No & $430(86.7 \%)$ & $66(13.3 \%)$ & \multirow[t]{2}{*}{$9.14(1.85,45.16)$} & \multirow[t]{2}{*}{$0.0066^{* *}$} \\
\hline & Yes & $3(37.5 \%)$ & $5(62.5 \%)$ & & \\
\hline
\end{tabular}

* - statistically significant at the 0.05 level

** - statistically significant at the 0.01 level 


\section{$\%$ converted}

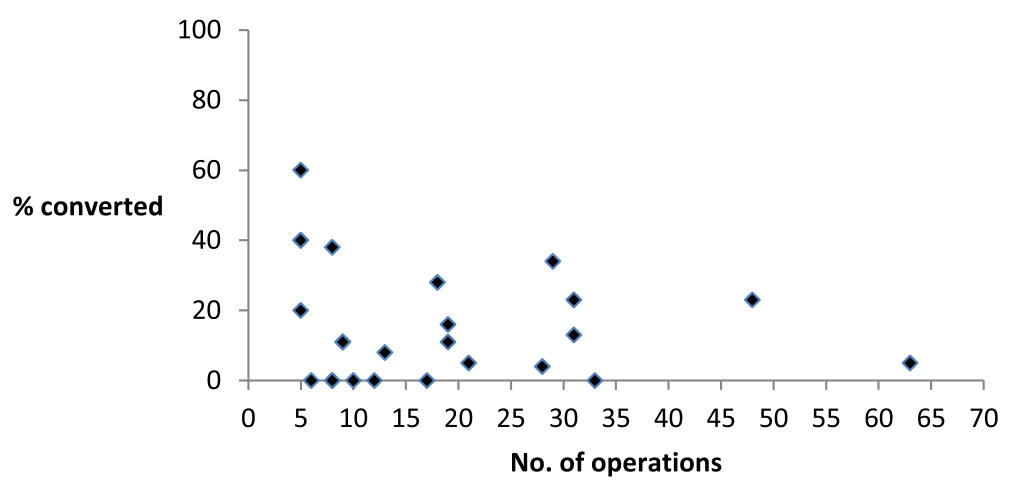

Fig. 1 The relationship between the number of cholecystectomies performed and conversion, $(r h o=-0.17)$

are paradigm shifts in the management of biliary disease $[21,22]$.

The cholecystectomy rate varies geographically, but is generally undertaken in between 100 to 200 per 100,000 inhabitants [23]. In the UK, $41 \%$ of patients have been admitted with prior cholecystitis before their eventual cholecystectomy [24].

Other large series have somewhat similar conversion rates although $\mathrm{Hu}$ and colleagues report only a $4 \%$ conversion rate $[6,11,25]$. There is extreme variability in the conversion rate in our study, and there is no reason to believe this does not reflect true practice. Even if we exclude surgeons who contributed less than five cases, the variability in conversion is from 0 to $60 \%$ with an average of $14 \%$. As the volume of surgery increased, the conversion rate decreased. A weakness of this study was that we cannot be sure that all surgeons enrolled consecutive patients. This issue begs questions about surgical skills and techniques used to facilitate the safe completion of laparoscopic cholecystectomy. It highlights the potential needs for data registries and key performance indicators to provide meaningful analysis $[4,18,26]$. This would help both with surgical training and patient safety. This is crucially important with morbidity rates approaching $30 \%$, and mortality of $5 \%$ after cholecystectomy, especially if the emergency cohorts are included.

Table 5 Prevalence of risk factors in those with and without complications

\begin{tabular}{|c|c|c|c|}
\hline \multirow{2}{*}{ Risk factors } & \multirow[t]{2}{*}{ Level } & \multicolumn{2}{|l|}{ Outcome } \\
\hline & & $\begin{array}{l}\text { No intraoperative } \\
\text { complications no. (\%) }\end{array}$ & $\begin{array}{l}\text { Intraoperative } \\
\text { complications no. (\%) }\end{array}$ \\
\hline \multirow[t]{3}{*}{ Gallbladder (GB) appearance } & Adhesions covering $<50 \%$ of $\mathrm{GB}$ & $274(95.8 \%)$ & $12(4.2 \%)$ \\
\hline & Adhesions > 50\% but GB visible & $120(91.6 \%)$ & $11(8.4 \%)$ \\
\hline & Completely buried GB & $80(92 \%)$ & $7(8 \%)$ \\
\hline \multirow[t]{2}{*}{ BMl } & $\leqq 30$ & $325(94.2 \%)$ & $20(5.8 \%)$ \\
\hline & $>30$ & $149(93.7 \%)$ & $10(6.3 \%)$ \\
\hline \multirow[t]{2}{*}{ Adhesions from previous surgery limiting access } & No & $424(94 \%)$ & $27(6 \%)$ \\
\hline & Yes & $50(94.3 \%)$ & $3(5.7 \%)$ \\
\hline \multirow[t]{2}{*}{ Distended or shrivelled GB } & No & $260(92.5 \%)$ & $21(7.5 \%)$ \\
\hline & Yes & $214(96 \%)$ & $9(4 \%)$ \\
\hline \multirow[t]{2}{*}{ Inability to grasp GB } & No & $330(94.8 \%)$ & $18(5.2 \%)$ \\
\hline & Yes & $144(92.3 \%)$ & $12(7.7 \%)$ \\
\hline \multirow[t]{2}{*}{ Stone $1 \mathrm{~cm}$ impacted in Hartmann's pouch } & No & $342(95.3 \%)$ & $17(4.7 \%)$ \\
\hline & Yes & $132(91 \%)$ & $13(9 \%)$ \\
\hline \multirow[t]{2}{*}{ Bile or pus outside GB } & No & $415(94.8 \%)$ & $23(5.2 \%)$ \\
\hline & Yes & 59 (89.4\%) & $7(10.6 \%)$ \\
\hline \multirow[t]{2}{*}{ Fistula } & No & 467 (94.2\%) & $29(5.8 \%)$ \\
\hline & Yes & 7 (87.5\%) & 1 (12.5\%) \\
\hline
\end{tabular}


With the ability to predict pre-operative difficult surgery, perhaps surgeons may increasingly opt out, explaining in part the increasing use of percutaneous cholecystostomy [27]. Almost 20\% of patients in Hall's cohort underwent PC cholecystostomy, with almost four times the complication rate of those undergoing emergency laparoscopic cholecystectomy. This needs to be balanced however by selection bias, potentially including more seriously ill patients in the cholecystostomy route [28]. Future research relating to conversion from laparoscopic to open cholecystectomy should report the percutaneous cholecystostomy rate. Previous suggestions that PC cholecystostomy is a desirable alternative to cholecystectomy are now in doubt [29]. The AUC for the G10 was 0.772 which is less than Hu's recent reported Cairns Prediction Model with an AUC of 0.87 [25]. Their prediction model utilised three ultrasonographic and two clinical parameters. It is a pre-operative grading system. External validation had taken place with both Sutcliffe's and Goonawardena's predictive models with good AUC outcomes, only falling from 0.81 to 0.77 and 0.97 to 0.87 respectively $[9,30]$.

The current study has a number of limitations in part due to the desire to ensure simplifying surgeons involvement and ensure a broad ethically agreed international input. The question as to whether this is a validation study or development of a new score is important, but the changes between the first study in terms of scoring criteria were limited but need to be noted. Ideally developing a scoring system needs two stages, the development and its validation, and a much broader validation would be ideal. Surgeons when enrolling were not asked if their cases were consecutive nor asked to report exclusions. Furthermore, subjective opinion of the operating surgeon was accepted when grading the gallbladder appearance. Unlike other studies, photographic documentation of intra-operative findings was not required and operative pictures and videos were not uploaded or analysed [10]. This may have introduced bias in the study, but given the complexity of organising and ethical issues in storing patient data from 16 countries, this was not done. Inter-observer error when grading adhesions which limit surgery is rather subjective, and inter-observer variability has been reported in other laparoscopic assessment and grading, with a recent study in appendicitis showing poor reproducibility [31]. Our study only requested whether an intra-operative complication occurred or not and further descriptors were not requested. This prohibited significant analysis but was utilised to encourage engagement of surgeons as it was felt that underreporting would occur with surgeons reticent to enter this data into an international database. This reluctance has recently been reported with significant underreporting by surgeons of their intra-operative complications [32].
A key to optimising outcomes in cholecystectomy is a laparoscopic approach, albeit with a slightly increased risk of bile duct injury, and the latest Tokyo consensus emphasize that conversion to open is not a complication and in fact may be safer than pursuing the laparoscopic route in individual cases [5]. Bailout is an important option as surgeons may not possess the experience required for a complex open case. Conversion is not always a crime [33].

Grading systems have identified risk factors for both prolonged surgery and increased need for conversion. Wakabayashi et al. identified 19 operative risk factors potentially contributing to conversion [5]. As surgeons, we know that there are unique variable technical difficulties encountered during cholecystectomy and these fundamentally are related to the access, adhesion density and vascularity and the thickness, friability and weight and thickness of the gallbladder [34]. Recently, Wakabayashi et al., as part of the Tokyo 2018 guidelines, suggested 25 operative findings with scores that may affect the technical difficulty of cholecystectomy [5]. While we would disagree with Lee's statement that there is no organised operative grading system, this study, and our previous study, suggests that the grading or scoring systems can be improved even further $[7,35]$.

The G10 score itself, while easy to perform, was not validated by independent photographic assessment or review of operative data. Unquestionably, there is a need for stratification of gallbladder severity in patients undergoing cholecystectomy. The Tokyo guidelines, like others, have not focused on operative finding when reporting outcomes [36]. The G10 score which was developed to anticipate conversion rate was therefore not used to study complications in this paper.

A disadvantage of the G10 is that it is an operative scoring system and patients who have interventions without surgery cannot be assessed. Patients undergoing percutaneous cholecystostomy who subsequently undergo surgery can be included. Given the mortality of high-risk cholecystitis patients, this needs to be addressed. This might help establish recent suggestions that percutaneous cholecystostomy is inferior to cholecystectomy [27]. The current is one of the largest reported prospective studies and adds to the debate about the benefits of both scores and grades in cholecystitis [34].

\section{Conclusion}

This study has identified the need for greater understanding of conversion rates and readmission rates. The international surgical community needs to come to grips with the metrics of cholecystitis and cholecystectomy. The adoption of an agreed peri-operative grading or score of gallbladder disease and surgery is essential to advance the road to improved outcomes for our patients with biliary disease. The optimal cut-off point was a G10 score of 3 to predict conversion to open cholecystectomy. Conversion 
occurred in $33 \%$ of patients with G10 scores of $\geq 5$. The four variables statistically predictive of conversion were GB appearance-completely buried GB, impacted stone, bile or pus outside GB and fistula. The G10 operative scores provide simple grading of operative cholecystectomy and are predictive of the need to convert to open cholecystectomy. Broader adaptation and validation may provide a benchmark to understand and improve care and afford more standardisation in global comparisons of care for cholecystectomy.

\section{Abbreviations}

CBD: Common bile duct; ERCP: Endoscopic retrograde cholangiopancreatography; GB: Gallbladder; IOC: Intra-operative cholangiography; WSES: World Society of Emergency Surgery

\section{Acknowledgements}

We wish to acknowledge the support of EU's INTERREG VA Programme, managed by the Special EU Programmes Body (SEUPB).

We would like to also acknowledge Asaf Harbi, Stefano Magnone, Roberto Manfredi, Poletti de Chaurand Eugenio, Nicola Colaianni, Michela Giulli Capponi, Marco Lotti, Francesca Rubertà, Michela Capponi and Dario Piazzalunga who contributed to cases.

Contributors from WSES: Dimitrios Manatakis ${ }^{1}$, Orestis loannidis ${ }^{2}$, Stefano Bonilauri ${ }^{3}$, Mahir Gachabayov ${ }^{4}$, Arda Isik', Wagih Ghnnam ${ }^{6}$, Vishal Shelat ${ }^{7}$, Muyiwa Aremu ${ }^{8}$, Rajashekar Mohan ${ }^{9}$, Giulia Montori ${ }^{10}$, Maciej Walędziak ${ }^{11}$, Magdalena Pisarska ${ }^{12}$, Victor Kong ${ }^{13}$, Marcin Strzałka ${ }^{14}$, Paola Fugazzola ${ }^{10}$, Gabriela Elisa Nita ${ }^{15}$, Matteo Nardi ${ }^{16}$, Piotr Major ${ }^{17}$, lonut Negoi ${ }^{18}$, Andrea Allegri ${ }^{10}$, Georgios Konstantoudakis ${ }^{19}$, Isidoro Di Carlo ${ }^{20}$, Damien Massalou ${ }^{21}$, Giuseppe D'Amico ${ }^{22}$, Leonardo Solaini ${ }^{10}$, Marco Ceresoli ${ }^{23}$, Roberto Bini ${ }^{24}$, Martin Zielinski ${ }^{25}$, Matteo Tomasoni ${ }^{10}$, Andrey Litvin ${ }^{26}$, Belinda De Simone ${ }^{27}$, Eftychios Lostoridis ${ }^{28}$, Fernando Hernandez ${ }^{29}$, Gabor Panyor ${ }^{10}$, Gustavo M. Machain $V^{30}$, loanna Pentara ${ }^{31}$, Luca Baiocchi ${ }^{32}$, Kin Cheung $\mathrm{Ng}^{8}$, Luca Ansaloni ${ }^{10}$, Massimo Sartelli $i^{33}$, Miguel Leon Arellano ${ }^{34}$, Natalia Savala ${ }^{35}$, Neville Couse ${ }^{8}$, Sarah McBride ${ }^{8}$.

${ }^{1}$ St Savvas Cancer Hospital, Athens, Greece. dmanatak@yahoo.gr ${ }^{2} 4$ th Surgical Department, Medical School, Aristotle University of Thessaloniki, Thessaloniki, Greece. telonakos@hotmail.com ${ }^{3}$ Arciospedale Santa Maria Nuova, Reggio Emilia, Italy. Stefano.Bonilauri@ausl.re.it ${ }^{4}$ Vladimir City Clinical Hospital of Emergency Medicine, Vladimir, Russia. gachabayovmahir@gmail.com ${ }^{5}$ Breast Surgical Oncology Research Scholar, Pittsburgh University, Magee-Womens Hospital. USA. kararda@yahoo.com ${ }^{6}$ Mansoura faculty of medicine Mansoura University, Egypt.wghnnam@gmail.com ${ }^{7}$ Tan Tock Seng Hospital, Singapore. vishal_9_shelat@ttsh.com.sg ${ }^{8}$ Dept of Surgery, Letterkenny University Hospital, Donegal, Ireland. maremu@rcsi.ie; ngkc@tcd.ie; neville.couse@hse.ie; michael.sugrue@hse.ie ${ }^{9}$ K.S. Hegde Medical Academy of NITTE Deemed to be University, Mangalore, Karnataka, India. rajshekarm@rediffmail.com, ${ }^{10} \mathrm{HPG} 23$, Bergamo, Italy.giulia.montori@gmail.com; andrea.happy83@gmail.com; leonardosolaini@gmail.com; matteotomasoni83@gmail.com; gabor.panyor@gmail.com; giulia.montori@gmail.com ${ }^{11}$ Department of General, Oncological, Metabolic and Thoracic Surgery; Military Institute of Medicine in Warsaw, Warsaw. Poland. maciej.waledziak@gmail.com ${ }^{12}$ Department of Endoscopic, Metabolic and Soft Tissue Tumors Surgery, Kraków. magdalenapisarska@ interia.pl ${ }^{13}$ Department of Surgery, Edendale Hospital, Pietermaritzburg, South Africa. victorywkong@yahoo.com ${ }^{14}$ Department of General Surgery, Polytrauma and Emergency Medicine, Jagiellonian University Medical College, Kraków, Poland. marcin.strzalka@uj.edu.pl ${ }^{15}$ Ospedale Sant'Anna, Castelnovo ne' Monti. Italy. nitagabriela2001@yahoo.com ${ }^{16}$ Infermi Hospital, Rimini, Italy. matteonardi@live.com, ${ }^{17}$ 2nd Department of General Surgery, Jagiellonian University Medical College, Krakow. Poland. majorpiotr@gmail. com ${ }^{18} \mathrm{Carol}$ Davila University of Medicine and Pharmacy Bucharest, Emergency Hospital of Bucharest, Bucharest, Romania. negoiionut@gmail. com ${ }^{19}$ Nafplion General Hospital, Nafplion, Greece. gkonstmd@hotmail.com ${ }^{20}$ Department of Surgical Sciences and Advanced Technologies. University of Catania, General Surgery, Cannizzaro Hospital.Catania. Italy. idicarlo@unict.it ${ }^{21}$ Acute care surgery, University Hospital of Nice, CHU de Nice, Université Nice. Côte d'Azur, France. massalou.d@chu-nice.fr ${ }^{22}$ Transplantation Center, Department of General Surgery, Digestive Disease and Surgery Institute,
Cleveland Clinic, Cleveland, OH, USA. giudamico86@hotmail.it ${ }^{23}$ General and Emergency Surgery, University of Milano-Bicocca, Monza, Italy. marco. ceresoli89@gmail.com ${ }^{24}$ SG Bosco Hospital, Turin, Italy. re.bini@libero.it ${ }^{25}$ Mayo Clinic, Rochester. USA. zielinski.martin@mayo.edu ${ }^{26}$ Immanuel Kant Baltic Federal University, Regional Clinical Hospital, Kaliningrad, Russia. aalitvin@gmail.com ${ }^{27}$ Regional Hospital of Perpignan, France. desimone. belinda@gmail.com ${ }^{28} 1$ st Department of Surgery, Kavala General Hospital, Kavala, Greece. e.lostoridis@gmail.com ${ }^{29}$ Departamento de cirugía de trauma, Hospital Central Militar, Mexico. fernando_hdez44@hotmail.com ${ }^{30}$ Universidad Nacional de Asunción. Facultad de Ciencias Medicas. Hospital de Clinicas. II Catedra de Cirugía. Paraguay. Gmmachain@yahoo. com ${ }^{31}$ Nafplion General Hospital, Nafplion, Greece. joanpen2@yahoo.ge, ${ }^{32}$ Unit of General Surgery, University of Brescia, Italy. gianluca.baiocchi@ unibs.it ${ }^{33}$ Macerata Hospital, Macerata, Italy. massimosartelli@gmail.com ${ }^{34}$ Hospital Fundación Jimenez Diaz, Madrid, Spain. miquel.leon. arellano@gmail.com ${ }^{35} 4$ th Surgical Department, Medical School, Aristotle University of Thessaloniki, Thessaloniki, Greece. nataliasavalamd@gmail.com

\section{Funding}

Not applicable

\section{Availability of data and materials}

The data-sets used and/or analysed during the current study are available from the corresponding author on reasonable request.

\section{Authors' contributions}

FC supplied the database. MS, MB, and AJ analysed the data. All authors contributed to the cases. MS wrote the first draft of the manuscript. All the authors reviewed and approved the final draft.

\section{Authors' information}

Not applicable

\section{Ethics approval and consent to participate}

Ethical approval for the audit was obtained from each contributor's individual institution. Consent to participate was not applicable.

\section{Consent for publication}

Not applicable

\section{Competing interests}

Michael Sugrue is a consultant with Smith \& Nephew and Acelity.

\section{Publisher's Note}

Springer Nature remains neutral with regard to jurisdictional claims in published maps and institutional affiliations.

\section{Author details}

${ }^{1}$ Donegal Clinical Research Academy, Letterkenny University Hospital, Donegal, Ireland. ${ }^{2}$ Papa Giovanni Hospital, Bergamo, Italy. ${ }^{3}$ EU INTERREG Centre for Personalised Medicine, Intelligent Systems Research Centre, School of Computing, Engineering and Intelligent Systems, Ulster University, Magee Campus, Derry Londonderry, Northern Ireland.

Received: 3 January 2019 Accepted: 27 February 2019 Published online: 14 March 2019

\section{References}

1. Lombardo S, Rosenberg J, Kim J, Erdene S, Sergelen O, Nellermoe J, Finlayson S, Price R. Cost and outcomes of open versus laparoscopic cholecystectomy in Mongolia. J Surg Res. 2018;229:186-91.

2. van de Graaf F, van den Bos J, Stassen L, Lange J. Lacunar implementation of the critical view of safety technique for laparoscopic cholecystectomy: results of a nationwide survey. Surgery. 2018;164(1):31-9.

3. Pitt HA. Patient value is superior with early surgery for acute cholecystitis. Ann Surg. 2014;259:16-7.

4. Sugrue M, Maier R, Moore E, Boermeester M, Catena F, Coccolini F, Leppaniemi A, Peitzman A, Velmahos G, Ansaloni L, Abu-Zidan F. Proceedings of resources for optimal care of acute care and emergency surgery consensus summit Donegal Ireland. World J Emerg Surg. 2017; 12(1):47. 
5. Wakabayashi G, Iwashita Y, Hibi T, Takada T, Strasberg S, Asbun H, Endo I, Umezawa A, Asai K, Suzuki K, Mori Y. Tokyo Guidelines 2018: surgical management of acute cholecystitis: safe steps in laparoscopic cholecystectomy for acute cholecystitis (with videos). J Hepatobiliary Pancreat Sci. 2018;25(1):73-86.

6. Vera K, Pei K, Schuster K, Davis K. Validation of a new American Association for the Surgery of Trauma (AAST) anatomic severity grading system for acute cholecystitis. J Trauma Acute Care Surg. 2018;84(4):650-4.

7. Sugrue M, Sahebally S, Ansaloni L, Zielinski M. Grading operative findings at laparoscopic cholecystectomy- a new scoring system. World J Emerg Surg. 2015;10:14. https://doi.org/10.1186/s13017-015-0005-x.

8. Bharamgoudar R, Sonsale A, Hodson J, Griffiths E, CholeS Study Group, West Midlands Research Collaborative. The development and validation of a scoring tool to predict the operative duration of elective laparoscopic cholecystectomy. Surg Endosc 2018; 32(7):3149-3157.

9. Sutcliffe R, Hollyman M, Hodson J, Bonney G, Vohra R, Griffiths E, Fenwick S, Elmasry M, Nunes Q, Kennedy D, Khan R. Preoperative risk factors for conversion from laparoscopic to open cholecystectomy: a validated risk score derived from a prospective UK database of 8820 patients. J Hepatobiliary Pancreat Sci. 2016;18(11):922-8.

10. Madni T, Leshikar D, Minshall C, Nakonezny P, Cornelius C, Imran J, Clark A, Williams B, Eastman A, Minei J, Phelan $\mathrm{H}$. The Parkland grading scale for cholecystitis. Am J Surg. 2018;215(4):625-30.

11. Hernandez M, Murphy B, Aho J, Haddad N, Saleem H, Zeb M, Morris D, Jenkins D, Zielinski M. Validation of the AAST EGS acute cholecystitis grade and comparison with the Tokyo guidelines. Surgery. 2018;163(4):739-46.

12. Yokoe M, Takada T, Strasberg S, Solomkin J, Mayumi T, Gomi H, Pitt H, Gouma D, Garden O, Büchler M, Kiriyama S. New diagnostic criteria and severity assessment of acute cholecystitis in revised Tokyo Guidelines. J Hepatobiliary Pancreat Sci. 2012;19(5):578-85.

13. World Society of Emergency Surgery Trials Registry. G10-Trial.2016. Available on-line at https://www.wses.org.uk/trials

14. Ansaloni L, Pisano M, Coccolini F, Peitzmann A, Fingerhut A, Catena F, Agresta F, Allegri A, Bailey I, Balogh Z, Bendinelli C. 2016 WSES guidelines on acute calculous cholecystitis. World J Emerg Surg. 2016;11(1):25. https:// doi.org/10.1186/s13017-016-0082-5.

15. Griffiths E. Two operative grading systems to define the difficulty of cholecystectomy. Comment in response to: Sugrue M, Sahebally S, Ansaloni L, Zielinski M. Grading operative findings at laparoscopic cholecystectomy- a new scoring system. World J Emerg Surg. 2015;10:14. https://doi.org/10. 1186/s13017-015-0005-x

16. Sheffield K, Ramos K, Djukom C, Jimenez C, Mileski W, Kimbrough T, Townsend C Jr, Riall T. Implementation of a critical pathway for complicated gallstone disease: translation of population-based data into clinical practice. J Am Coll Surg. 2011:212(5):835-43.

17. Litynski G. Erich Mühe and the rejection of laparoscopic cholecystectomy (1985): a surgeon ahead of his time. J Soc Laparoendosc Surg. 1998;2(4):341.

18. Ogola G, Crandall M, Shafi S. Variations in outcomes of emergency general surgery patients across hospitals: a call to establish emergency general surgery quality improvement program. J Trauma Acute Care Surg. 2018;84(2):280-6.

19. Hanna G, Shimi S, Cuschieri A. Randomised study of influence of twodimensional versus three-dimensional imaging on performance of laparoscopic cholecystectomy. Lancet. 1998;351(9098):248-51.

20. Nassar A, Ashkar K, Mohamed A, Hafiz A. Is laparoscopic cholecystectomy possible without video technology? Min Invas Ther. 1995;4(2):63-5.

21. Guan G, Sun C, Ren Y, Zhao Z, Ning S. Comparing a single-staged laparoscopic cholecystectomy with common bile duct exploration versus a two-staged endoscopic sphincterotomy followed by laparoscopic cholecystectomy. Surgery. 2018:164(5):1030-4.

22. Pan $L$, Chen M, Ji L, Zheng L, Yan P, Fang J, Zhang B, Cai X. The safety and efficacy of laparoscopic common bile duct exploration combined with cholecystectomy for the management of cholecysto-choledocholithiasis: an up-to-date meta-analysis. Ann Surg. 2018;268(2):247-53.

23. Noel R, Arnelo U, Enochsson L, Lundell L, Nilsson M, Sandblom G. Regional variations in cholecystectomy rates in Sweden: impact on complications of gallstone disease. Scand J Gastroenterol. 2016;51(4):465-71.

24. CholeS Study Group, West Midlands Research Collaborative, Vohra R, Pasquali S, Kirkham A, Marriott P, Johnstone M, Spreadborough P, Alderson D, Griffiths E, Fenwick S, Elmasry M. Population-based cohort study of outcomes following cholecystectomy for benign gallbladder diseases. $\mathrm{Br}$ J Surg. 2016;103(12):1704-15.
25. Hu A, O'Donohue P, Gunnarsson R, de Costa A. External validation of the Cairns Prediction Model (CPM) to predict conversion from laparoscopic to open cholecystectomy. Am J Surg. 2018;216(5):949-54.

26. Törnqvist B, Strömberg C, Persson G, Nilsson M. Effect of intended intraoperative cholangiography and early detection of bile duct injury on survival after cholecystectomy: population based cohort study. BMJ. 2012; 345:e6457.

27. Hall B, Armijo P, Krause C, Burnett T, Oleynikov D. Emergent cholecystectomy is superior to percutaneous cholecystostomy tube placement in critically ill patients with emergent calculous cholecystitis. Am J Surg. 2017;216(1):116-9.

28. Yeo C, Tay V, Low J, Woon W, Punamiya S, Shelat V. Outcomes of percutaneous cholecystostomy and predictors of eventual cholecystectomy. J Hepatobiliary Pancreat Sci. 2016;23(1):65-73.

29. Cherng N, Witkowski E, Sneider E, Wiseman J, Lewis J, Litwin D, Santry H, Cahan M, Shah S. Use of cholecystostomy tubes in the management of patients with primary diagnosis of acute cholecystitis. J Am Coll Surg. 2012; 214(2):196-201

30. Goonawardena J, Gunnarsson R, De Costa A. Predicting conversion from laparoscopic to open cholecystectomy presented as a probability nomogram based on preoperative patient risk factors. Am J Surg. 2015; 210(3):492-500.

31. van den Boom A, de Wijkerslooth E, Mauff K, Dawson I, van Rossem C, Toorenvliet B, Wijnhoven B. Interobserver variability in the classification of appendicitis during laparoscopy. Br J Surg. 2018;105(8):1014-9.

32. Peponis T, Baekgaard J, Bohnen J, Han K, Lee J, Saillant N, Fagenholz P, King $D$, Velmahos $\mathrm{G}$, Kaafarani $\mathrm{H}$. Are surgeons reluctant to accurately report intraoperative adverse events? A prospective study of 1,989 patients. Surgery. 2018. Article in press; available online at. https://doi.org/10.1016/j. surg.2018.04.035.

33. Amirthalingam V, Low J, Woon W, Shelat V. Tokyo Guidelines 2013 may be too restrictive and patients with moderate and severe acute cholecystitis can be managed by early cholecystectomy too. Surg Endosc. 2017;31(7): 2892-900.

34. Sugrue M, Sahebally S, Ansaloni L, Zielinski M, Coccolini F. In response to the article entitled "The Parkland grading scale for cholecystitis" by Madni et al. In Madni T, Leshikar D, Minshall C, Nakonezny P, Cornelius C, Imran J, Clark A, Williams B, Eastman A, Minei J, Phelan H. The Parkland grading scale for cholecystitis. In Am J Surg; 2017 Jun 6. doi. org/10.1016/j. amjsurg. 2017. 05. 017. Am J Surg. 2018. https://doi.org/10.1016/j.amjsurg.2018.01.029.

35. Lee W, Jang J, Cho J, Hong S, Jeong C. Does surgical difficulty relate to severity of acute cholecystitis? Validation of the Parkland grading scale based on intraoperative findings. Am J Surg. 2018; Article in press; available online at https://doi.org/10.1016/j.amjsurg.2018.12.005.

36. Lal P, Agarwal P, Malik V, Chakravarti A. A difficult laparoscopic cholecystectomy that requires conversion to open procedure can be predicted by preoperative ultrasonography. J Soc Laparoendosc Surg. 2002; 6:59-63.
Ready to submit your research? Choose BMC and benefit from:
- fast, convenient online submission
- thorough peer review by experienced researchers in your field
- rapid publication on acceptance
- support for research data, including large and complex data types
- gold Open Access which fosters wider collaboration and increased citations
- maximum visibility for your research: over $100 \mathrm{M}$ website views per year
At $\mathrm{BMC}$, research is always in progress.
Learn more biomedcentral.com/submissions 